\title{
Factors Affecting Clinical Outcome of Patients with Traumatic Brain Injury
}

\author{
Deepali Rishi Rajpal' ${ }^{1}$ Sachna Pramod Shetty ${ }^{1}$, Manhar Shah ${ }^{1}$ \\ ${ }^{1}$ Department of Emergency Medicine, Dr. DY Patil University School of Medicine, Navi Mumbai, Maharashtra.
}

\section{Abstract}

Background: The present study aims to describe the severity of injury [Glasgow Coma Scale (GCS)] and outcome of patients [Glasgow Outcome Scale (GOS)] who presented to our hospital with TBI and factors which affect the clinical outcome. Subjects and Methods: All patients, aged equal to or more than 18 years, presenting to the Emergency Department of our hospital due to head trauma during the study period were examined and assessed using GCS at the time of admission, and GOS at the time of discharge. Results: The most common mode of injury was road traffic accident (48\%). At the time of admission, 47\% had GCS of 13 to $15,37 \%$ had GCS of 9 to 12 and $16 \%$ had GCS of 3 to 8 . At the time of discharge, we found that 18 patients had GOS of 1, no patient had GOS of 2, 14 patients had GOS Of 3 , 28 had GOS of 4 and 29 had GOS of 5. We found that age of the patients was significantly associated with the GOS severity (p value <0.05). Furthermore, GCS at admission was found to be significantly associated with GOS at discharge (p value <0.01). Midline shift on CT head, effaced basal cistern, and presence of subarachnoid haemorrhage were also found to be significantly associated with poor GOS at discharge. Conclusion: The results of our study may be used for stratification of patients, and developing prognostic models to improve the clinical outcome of head injury.

Keywords: Glasgow Coma Scale; Glasgow Outcome Scale; Head trauma; Vehicle injury.

Corresponding Author: Dr. Sachna Pramod Shetty, Department of Emergency Medicine, Dr. DY Patil University School of Medicine, Navi Mumbai, Maharashtra.

Email: research2016gmc@gmail.com

Received: March 2020

Accepted: March 2020

Introduction

The World Health Organisation defines Traumatic Brain Injury (TBI) as an occurrence of injury to the head with at least one of the following: observed or self-reported alteration of consciousness or amnesia due to head trauma, neurologic or neuropsychological or diagnoses of skull fracture or intracranial lesions that can be attributed to the head trauma. ${ }^{[1]}$ The burden of TBI in India is unknown, but estimates suggest that there are more than a million trauma related deaths in India per year, of which 50\% are TBI related. An epidemiological study in Bangalore indicates that the incidence, mortality and case fatality rates were $150 / 1,00,000,20 / 1,00,000$ and $10 \%$, respectively. ${ }^{[2]}$ The most common cause of TBI normally reported in our country are road traffic accidents (RTA) accounting for $60 \%$, followed by falls and assaults contributing to $25 \%$ and $10 \%$ of traumatic brain injuries respectively. ${ }^{[2]}$ The Glasgow Coma Scale (GCS) is one of the most commonly used tools by trauma care providers as it enables the gradation of head injury severity using simple observations rather than invasive or specialist techniques. Bryan Jennett and Michael Bond published a complementary scale, the Glasgow Outcome Scale (GOS), designed to assess outcomes of brain injury. ${ }^{[3]}$ Not only the patient but their relatives and the treating physician are concerned about the outcomes of head injury. Of these, residual neurological defects after recovery from a head injury are a major concern. If an association between the severity of injury and outcomes can be found, the patients and their family members can be better counselled and be mentally prepared. The present study aims to describe the severity of injury (GCS) and outcome of patients (GOS) who presented to our hospital with TBI and factors which affect the clinical outcome.

\section{Subjects and Methods}

\section{Study Design and Sampling}

The present observation study was conducted in the Department of Emergency Medicine, DY Patil School of Medicine from July to December 2019. Complete information of this study, along with purpose of the study was given to patients or their attendants in their vernacular language. Data collection forms did not reveal name of the patients included in the study. Patients were included in the study after taking an informed consent from themselves or their legal guardian. All patients, aged equal to or more than 18 years, presenting to the Emergency Department of our hospital due to head trauma during the study period were included. We excluded patients with associated major abdominal, thoracic or bony injury, as these injuries can themselves affect the outcome scores or those with preceding significant morbid conditions which may affect the outcome scores (like Parkinsonism, Stroke, 
Degenerative diseases etc). The study was approved by the Institutional Ethics Committee.

\section{Data Collection and Data Analysis}

Using a predesigned semi-structured study proforma, patient data was collected. We obtained history including the mechanism of injury, any associated injuries, any pre existing disabilities. Examination included general examination, systemic examination for any other injuries. For evaluation of head injury at the time of admission, GCS, pupils, neurological deficits. Laboratory investigations were ordered as necessary. $\mathrm{X}$ rays were ordered as per injuries and trauma protocol. Non contrast computed tomography (NCCT) head was ordered on admission of all patients and repeated as per need. Outcome of the patients was assessed at the time of discharge using Glasgow Outcome Scale score: Grade I (death), Grade II (vegetative), Grade III (mostly dependant), Grade IV (minimally dependant) and Grade V (good recovery). The data were presented as mean and frequency distribution and analysed using chi-square or Fisher's exact test, with $p$ value $<0.05$ as statistically significant.

\section{Results}

In the present study, we included a total of 89 patients. Majority of the patients were aged less than 40 years of age, mean age of the patients was 38.5 years. Of all patients included, two thirds were males, from urban residences. The most common mode of injury was road traffic accident (48\%), falls and assault was reported by $30 \%$ and $21 \%$ of the patients respectively (Table 1). At the time of admission, $47 \%$ had GCS of 13 to $15,37 \%$ had GCS of 9 to 12 and $16 \%$ had GCS of 3 to 8. Approximately three fourths of all patients presented after 8 hours of injury. Physical examination revealed normal pupillary reflexes in $63 \%$, bilateral dilated pupils in $15 \%$ and anisocoria in $22 \%$ of the patients. Operative treatment was done for $31 \%$ and rest received conservative non-operative treatment. At the time of discharge, we found that 18 patients had GOS of 1 , no patient had GOS of 2, 14 patients had GOS Of 3, 28 had GOS of 4 and 29 had GOS of 5 (Figure 1). We found that age of the patients was significantly associated with the GOS severity ( $p$ value $<0.05$ ). Younger patients were found to have better GOS at discharge, while of 18 patients with GOS of 1, 10 were from age group greater than 40 years. Furthermore, GCS at admission was found to be significantly associated with GOS at discharge. Of the 18 patients with GOS of 1, 11 were had GCS of 3 to 8 at the time of admission ( $\mathrm{p}$ value $<0.01$ ). Midline shift on CT head was also found to be significantly associated with poor outcome at discharge as assessed by GOS ( $p$ value <0.05). In addition, effaced basal cistern, and presence of subarachnoid haemorrhage were also found to be significantly associated with poor GOS at discharge.

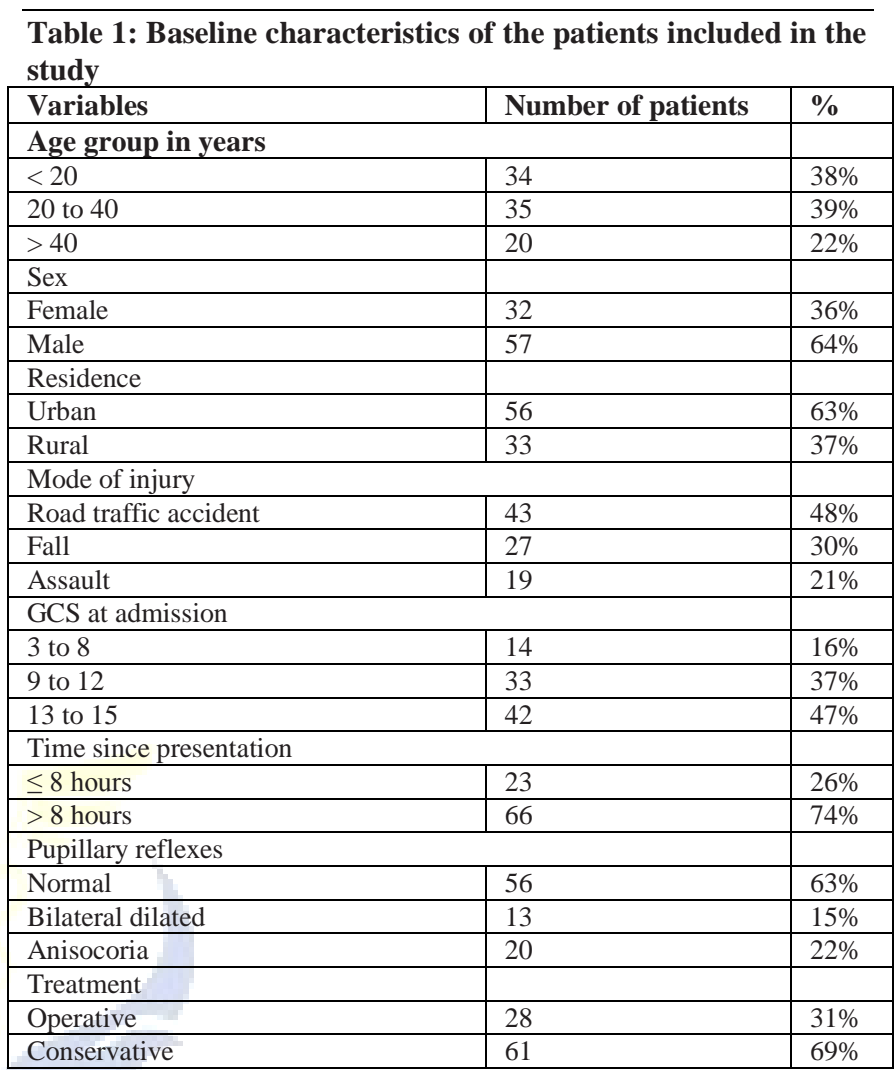

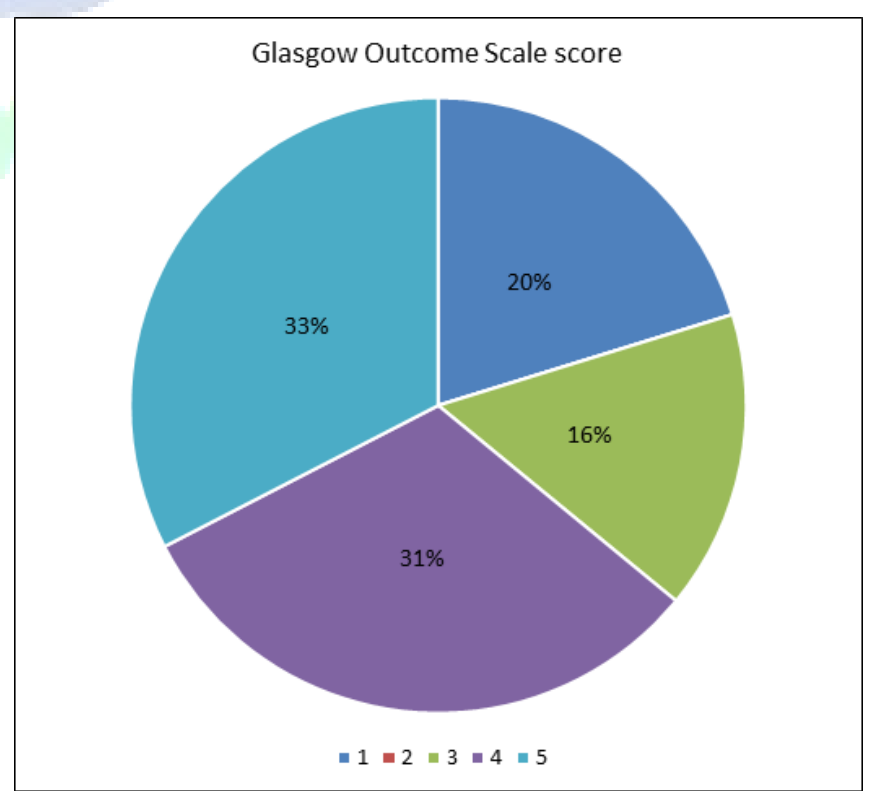

Figure 1: Distribution of patients according to their GOS at discharge

Table 2: Association of patient variable with GOS

\begin{tabular}{|c|c|c|c|c|c|c|}
\hline & \multicolumn{5}{|c|}{ Glasgow Outcome Scale } & \multirow[b]{2}{*}{ p value } \\
\hline & 1 & 2 & 3 & 4 & 5 & \\
\hline \multicolumn{7}{|c|}{ Age group (in years) } \\
\hline$<20$ & 2 & 0 & 4 & 14 & 14 & \\
\hline 20 to 40 & 6 & 0 & 5 & 11 & 13 & $<0.05(\mathrm{~S})$ \\
\hline
\end{tabular}


Rajpal et al; Factors Affecting Clinical Outcame of Patients with Traumatic Brain Injury

\begin{tabular}{|c|c|c|c|c|c|c|}
\hline$>40$ & 10 & 0 & 5 & 3 & 2 & \\
\hline & 18 & 0 & 14 & 28 & 29 & \\
\hline \multicolumn{7}{|l|}{ Sex } \\
\hline Female & 6 & 0 & 9 & 9 & 8 & \\
\hline \multirow[t]{2}{*}{ Male } & 12 & 0 & 5 & 19 & 21 & $>0.05(\mathrm{NS})$ \\
\hline & 18 & 0 & 14 & 28 & 29 & \\
\hline \multicolumn{7}{|l|}{ Mode of injury } \\
\hline Road traffic accident & 12 & 0 & 11 & 9 & 11 & \\
\hline Fall & 3 & 0 & 2 & 14 & 8 & $>0.05(\mathrm{NS})$ \\
\hline \multirow[t]{2}{*}{ Assault } & 3 & 0 & 1 & 5 & 10 & \\
\hline & 18 & 0 & 14 & 28 & 29 & \\
\hline \multicolumn{7}{|l|}{ GCS at admission } \\
\hline 3 to 8 & 11 & 0 & 3 & 0 & 0 & \\
\hline 9 to 12 & 4 & 0 & 8 & 13 & 8 & $<0.01(\mathrm{~S})$ \\
\hline \multirow[t]{2}{*}{13 to 15} & 3 & 0 & 3 & 15 & 21 & \\
\hline & 18 & 0 & 14 & 28 & 29 & \\
\hline \multicolumn{7}{|l|}{ CT findings } \\
\hline \multicolumn{7}{|l|}{ Midline shift } \\
\hline Present & 14 & 0 & 5 & 7 & 5 & \\
\hline \multirow[t]{2}{*}{ Absent } & 4 & 0 & 9 & 21 & 24 & $<0.05(\mathrm{~S})$ \\
\hline & 18 & 0 & 14 & 28 & 29 & \\
\hline \multicolumn{7}{|l|}{ Basal cistern } \\
\hline Effaced & 15 & 0 & 6 & 10 & 7 & \\
\hline \multirow[t]{2}{*}{ Uneffaced } & 3 & 0 & 8 & 18 & 22 & $<0.05(\mathrm{~S})$ \\
\hline & 18 & 0 & 14 & 28 & 29 & \\
\hline \multicolumn{7}{|c|}{ Subarachnoid haemorrhage } \\
\hline Present & 13 & 0 & 3 & 1 & 0 & \\
\hline \multirow[t]{2}{*}{ Absent } & 5 & 0 & 11 & 27 & 29 & $<0.05(\mathrm{~S})$ \\
\hline & 18 & 0 & 14 & 28 & 29 & \\
\hline
\end{tabular}

S: significant; NS: not significant

\section{Discussion}

In our study, at the time of admission, 47\% had GCS of 13 to $15,37 \%$ had GCS of 9 to 12 and $16 \%$ had GCS of 3 to 8 and at the time of discharge, we found that 18 patients had GOS of 1, no patient had GOS of 2, 14 patients had GOS Of 3, 28 had GOS of 4 and 29 had GOS of 5. We found that majority of the patients in our study were aged less than 40 years and were males. Nath et al also found that males contributed to a major chunk of the fraction amongst the injured (98\%), and most patients (36\%) were in 3rd decade of their life. ${ }^{[4]}$ Khan and colleagues studied the epidemiologic profile of patients with TBI admitted to a trauma center in Jaipur, India and found $84.6 \%$ were males, with an overall mean age of 36 years. ${ }^{[5]}$ The reason being the mobility of males is usually higher than females and they are exposed more to risk factors like RTAs, violence and work place accidents. ${ }^{[6]}$ TBIs in this young \& productive age group leads to loss of intellectual \& other faculties with a resulting burden on family $\&$ the society and should be explored in future studies. In addition, the most common mode of injury in our study was RTAs. Similar observations were made by Khan et al, ${ }^{[5]}$ Kumar et al, ${ }^{[7]}$ and Kamal et al. ${ }^{[8]}$ Possible reasons for such high proportion of head injury cases due to RTAs in India could be in the context of a very low degree of public health awareness about vehicular trauma, decreased legislation regarding violations for speeding, jumping red lights, restraining devices, helmets, and drink- driving.

We found that age of the patients was significantly associated with the GOS severity as younger patients were found to have better GOS at discharge. Similar results were shown by Livingston et al. ${ }^{[9]}$ Gómez et al showed that the chance of an adverse outcome was 10 times higher for patients over 35 years of age compared to those aged between 15 to 25 years. $^{[10]}$ Although, young are more frequent sufferers of TBI, elderly patients tend to have lower recovery rates than the young. ${ }^{[11]}$ Among older patient groups there is often a greater chance of comorbidity occurring along with the primary injury. ${ }^{[12]}$

In our study, GCS at admission was found to be significantly associated with GOS at discharge. Of the 18 patients with GOS of 1,11 were had GCS of 3 to 8 at the time of admission ( $p$ value <0.01). Khan et al reported similar observations and found that GCS score on admission of 8 had 70.6 times more mortality and those with a GCS score of 9-13 had 6.9 times more mortality compared with those with a GCS score of $13-14{ }^{[5]}$ Paydar et al also found that presenting GCS and the GCS on day 6 correlated significantly with the GOSE after one year. ${ }^{[13]}$ The lower the GCS on admission or day 6 , the poorer the GOSE score after one year. These differences were statistically significant with $\mathrm{p}=0.032$ and $\mathrm{p}=0.007$ on day 1 and day 6 , respectively. On the contrary, Oliveria et al found no association between categorical GCS at hospital admission (3-5 versus 6-8) and worst outcome according to GOS-LATE and concluded that GCS at hospital admission was also not indicative of worst prognosis. ${ }^{[14]}$ In addition, we observed that midline shift on CT head, effaced basal cistern, and presence of subarachnoid haemorrhage were also found to be significantly associated with poor GOS at discharge. Kumar et al reported that patients with multiple intracranial bleed (51.6\%), diffuse axonal injury (34\%) and diffuse subarachanoid haemorrhage (33.8\%) had higher 
mortality rates compared to other intracranial findings. ${ }^{[7]}$ Nelson et al, in their extended analysis of 861 TBI patients, found the midline shift as the most important parameter for prediction of favorable or unfavorable outcome. ${ }^{[15]}$ Effacement of basal cisterns on the initial computed tomography of the head correlated with unfavorable 30-day outcome in the study by Ogunlade et al as well. ${ }^{[16]}$

There are a few limitations of this study. Ours was a singlecenter study, with area-specific emergency medical transport services and emergent medical care in our hospital, which can vary across India. So our results might not be applicable to other geographical areas. Another important consideration to keep in mind is that only a proportion of all traumatic brain injuries will reach the hospital, and many of those with severe injuries may have died in the pre hospital setting, and many with mild injuries may not have sought clinical care, resulting in selection bias.

\section{Conclusion}

The results of our study may be used for prognostication, hypothesis generation and stratification of patients, and developing prognostic models, which can improve the understanding of the pathology, diagnosis, and treatment of head injury. Predictors of outcome in our study should be evaluated in other population and resource settings. This will eventually help the policy makers to streamline and optimize the emergency medical transport and medical management system in India.

\section{References}

1. Organisation WH: International Statistical Classification of Diseases and Related Health Problems. In., 10 edn. Geneva, Switzerland: WHO; 1992.

2. Gururaj G, Kolluri SV, Chandramouli BA, Subbakrishna DK, Kraus JF. Traumatic Brain Injury. Bangalore: National Institute of Mental Health and Neurosciences; 2005. [Last accessed on 2019 Dec 29]. Available

from: www.nimhans.kar.nic.in/epidemiology/doc/ep_ft25.pdf

3. Jennett B, Bond M. Assessment of outcome after severe brain damage: a practical scale. The Lancet. 1975;305(7905):480-4.

4. Nath HD, Tandon V, Mahapatra AK, Siddiqui SA, Gupta DK. Outcome of head injury in unknown patients at Level-1 apex trauma centre. Indian J Neurotrauma. 2011;8(1):11-5.

5. Khan KA, Choudhary M, Sinha VD, Gora N, Bairwa M. Predictors of Outcome After Traumatic Brain Injuries: Experience of a Tertiary Health Care Institution in Northwest India. World Neurosurgery. 2019;126:e699-705

6. Banerjee KK, Aggarwal BBL, Kohli A. Study of thoraco-abdominal injuries in Fatal Road Traffic Accidents in North East Delhi. Jour Med Toxicology. 1997; 14:40-43.

7. Kumar C, Sidram V, Kumar V, Raghavendra B. A clinicoepidemiological study of traumatic brain injury. Int J Surg Sci. 2019; 3(3): 88-93.

8. Kamal VK, Agrawal D, Pandey RM. Epidemiology, clinical characteristics and outcomes of traumatic brain injury: Evidences from integrated level 1 trauma center in India. J Neurosciences Rural Practice. 2016;7(4):515-20.

9. Livingstone DH, Lavery RF, Mosenthal AC, Knudson MM, Manley GT. Recovery at one year following isolated traumatic brain injury: a western trauma association prospective multicentre trial. J Trauma. 2005;59:1298e1303.

10. Gómez PA, Lobato R, Boto G, De la Lama A, González P, De la Cruz J. Age and outcome after severe head injury. Acta Neurochir. 2000;142(4):373-81.

11. Ghajar J. Traumatic brain injury. The Lancet. 2000;356(9233):923-9.

12. Guralnik JM. Assessing the impact of comorbidity in the older population. Ann Epidemiol. 1996;6(5):376-80.

13. Paydar S, Bordbar E, Taghipour M, Khalili H, Jafari M. Initial GCS and laboratory findings of patients with TBI are associated with the GOSE and mortality rate at one year. Int J Res Med Sci 2018;6:14-9

14. Oliveira RA, Araújo S, Falcão AL, Soares SM, Kosour C, Dragosavac D, Cintra EA, Cardoso AP, Thiesen RA. Glasgow outcome scale at hospital discharge as a prognostic index in patients with severe traumatic brain injury. Arquivos de neuropsiquiatria. 2012;70(8):6048.

15. Nelson DW, Nystrom H, MacCallum RM, Thornquist B, Lilja A, Bellander BM, et al. Extended analysis of early computed tomography scans of traumatic brain injured patients and relations to outcome. $\mathrm{J}$ Neurotrauma. 2010;27:5-9.

16. Ogunlade J, Elia C, Duong J, Yanez PJ, Dong F, Wacker MR, Menoni R, Goldenberg T, Miulli DE. Severe Traumatic Brain Injury Requiring Surgical Decompression in the Young Adult: Factors Influencing Morbidity and Mortality-A Retrospective Analysis. Cureus. 2018;10(7):34-9.

Copyright: (C) the author(s), 2020. It is an open-access article distributed under the terms of the Creative Commons Attribution License (CC BY 4.0), which permits authors to retain ownership of the copyright for their content, and allow anyone to download, reuse, reprint, modify, distribute and/or copy the content as long as the original authors and source are cited.

How to cite this article: Rajpal DR, Shetty SP, Shah M. Factors Affecting Clinical Outcome of Patients with Traumatic Brain Injury. Asian J. Med. Res. 2020;9(1):ME06-ME09.

DOI: dx.doi.org/10.47009/ajmr.2020.9.1.ME2

Source of Support: Nil, Conflict of Interest: None declared. 